\title{
Anionic Sites, Fucose Residues and Class I Human Leukocyte Antigen Fate During Interaction of Toxoplasma gondii with Endothelial Cells
}

\author{
Ana Carolina Stumbo, Helene Santos Barbosa*, Técia Maria Ulisses de Carvalho**, \\ Luís Cristóvão Porto, Laís de Carvalho/+ \\ Laboratório de Cultura de Células, Departamento de Histologia e Embriologia, Universidade do Estado do Rio de Janeiro, Av. \\ Prof. Manoel de Abreu 444, 3ํan andar, 20550-170 Rio de Janeiro, RJ, Brasil *Laboratório de Ultra-estrutura Celular, \\ Departamento de Ultra-estrutura e Biologia Celular, Instituto Oswaldo Cruz-Fiocruz, Rio de Janeiro, RJ, Brasil **Laboratório \\ de Ultra-estrutura Celular Hertha Meyer, IBCCF, UFRJ, Rio de Janeiro, RJ, Brasil
}

Toxoplasma gondii invades and proliferates in human umbilical vein endothelial cells where it resides in a parasitophorous vacuole. In order to analyze which components of the endothelial cell plasma membrane are internalized and become part of the parasitophorous vacuole membrane, the culture of endothelial cells was labeled with cationized ferritin or UEA I lectin or anti Class I human leukocytte antigen (HLA) before or after infection with $\mathrm{T}$. gondii. The results showed no cationized ferritin and UEA I lectin in any parasitophorous vacuole membrane, however, the Class I HLA molecule labeling was observed in some endocytic vacuoles containing parasite until 1 h of interaction with T. gondii. After 24 h parasite-host cell interaction, the labeling was absent on the vacuolar membrane, but presents only in small vesicles near parasitophorous vacuole. These results suggest the anionic site and fucose residues are excluded at the time of parasitophorous vacuole formation while Class I HLA molecules are present only on a minority of Toxoplasma-containig vacuoles.

Key words: Toxoplasma gondii - endothelial cells - ferritin - Ulex europaeus agglutinin-1 - histocompatibility antigens Class I

Recently there is an increasing interest in the Toxoplasma gondii, the agent of human and animal toxoplasmosis, the most common opportunistic protozoan infection of the central nervous system of individuals contaminated with HIV (Luft \& Remington 1992, Luft \& Chua 2000). This protozoan, an obligate intracellular parasite, is able to infect many eukariotic cells and is found within a membrane-bounded cytoplasmic vacuole designated as parasitophorous vacuole (PV). The vacuolar membrane incorporates components from both the host cell and the parasite, thus establishing an hybrid membrane (Nichols et al. 1983, Carvalho \& De Souza 1989, 1990, 1997, Carvalho et al. 1993, Pacheco-Soares \& De Souza 1998, Hakansson et al. 2001). Once within the PV, T. gondii multiplies even in professional phagocytic cells until complete destruction of the host cell. During the intracellular life cycle of the parasite there is no fusion of host cell lysosome with PV. However, lysosome-phagosome fusion and parasite destruction occur when fixed or antibody-coated live toxoplasms are interiorized by normal macrophages (Jones \& Hirsch 1972, Sibley 1989, Carvalho \& De Souza 1990). Therefore, these particular properties of the parasitophorous vacuole membrane (PVM) biogenesis and

This work has been supported by Faperj, CNPq, Uerj and Instituto Oswaldo Cruz-Fiocruz.

${ }^{+}$Corresponding author. Fax: +55-21-2587.6511. E-mail: laiscar@uerj.br

Received 28 August 2001

Acceptd 7 January 2002 maintenance have attracted the interest of many investigators since the PV is vital to the successful intracellular survival of T. gondii (Suss-Toby et al. 1996, Sinai \& Joiner 1997, 2001, Silverman \& Joiner 1997, Sinai et al. 1997, Lingelbach \& Joiner 1998, Mordue \& Sibley 1997, Mordue et al. 1999b).

In congenital toxoplasmosis, infection of endothelial cells lining the umbilical cord blood vessels is potentially the major transmission route to the foetus. Therefore, the study of invasion by $T$. gondii of cultured human umbilical vein endothelial cells (HUVEC) is of great interest since these cells are at the interface between the mother and the foetus (Dimier \& Bout 1993). Previous studies have shown that $T$. gondii invades and proliferates in HUVEC (Benedetto et al. 1997) where it resides in a PV. In order to analyse which components of the human endothelial cell plasma membrane are internalized and become part of the PVM, we used cationized ferritin as a marker of cell surface anionic sites and the Ulex europaeus agglutinin I (UEA I) lectin as marker for HUVEC since human endothelial cells contain exposed fucose residues (Holthöfer et al. 1982). We also used the monoclonal antibody against Class I human leukocyte antigen (HLA I) since these transmembrane glycoproteins are present in most of the eukariotic cells and play an important role in the immune response regulation.

\section{MATERIALS AND METHODS}

Parasites - Tachyzoites from the virulent RH strain of T. gondii were maintained by intraperitoneal passages in female Swiss mice, according to the conditions established by Colégio Brasileiro de Experimentação Animal (Cobea). The parasites were collected in phosphate buffer saline 
(PBS) $\mathrm{pH} 7.2,48$ to $72 \mathrm{~h}$ after infection. The suspension obtained from infected mice was centrifuged at $200 \mathrm{~g}$ for $10 \mathrm{~min}$ at room temperature to remove cells and debris, and the supernatant, which contained the parasites, was collected and centrifuged at $1,000 \mathrm{~g}$ for $10 \mathrm{~min}$. The pellet obtained was washed 2 or 3 times with PBS, pH 7.2, and resuspended to a density of $10^{6}$ parasites $/ \mathrm{ml}$ in PBS, $\mathrm{pH}$ 7.2. The parasites were used within 30 to $40 \mathrm{~min}$ after removal from the mouse peritoneal cavity, and the viability was evaluated using dye-exclusion test with Trypan blue.

HUVEC cultures - Human endothelial cells were obtained from umbilical cord veins by digestion with $0.06 \%$ collagenase type IA (Sigma Chemical Co., St. Louis, MO, USA) according to a method modified from Jaffe et al. (1973). HUVEC were resuspended in Dulbecco's modified Eagle's medium (DMEM) containing 20\% fetal calf serum, $50 \mu \mathrm{g} / \mathrm{ml}$ gentamicin and $2.5 \mu \mathrm{g} / \mathrm{ml}$ amphotericin. The cells were plated in plastic culture dishes $(35 \times 10 \mathrm{~mm})$ or in multiwell tissue culture plates with round coverslips that had been precoated with $0.1 \%$ porcine gelatin (Sigma Chemical Co., St. Louis, MO, USA). The cultures were maintained for $24-48 \mathrm{~h}$ at $37^{\circ} \mathrm{C}$ in $5 \% \mathrm{CO}_{2}$ atmosphere. The purity of the HUVEC cultures was verified by indirect immunofluorescent labeling with a rabbit anti-human von Willebrand factor antibody (Sigma Chemical Co., St. Louis, MO, USA) (Jaffe et al. 1974). The HUVEC used in all experiments were from primary cultures and most of the cells were positive for von Willebrand factor.

Anionic sites labeling - The HUVEC culture was washed in PBS pH 7.2 twice and incubated for $30 \mathrm{~min}$ at $4^{\circ} \mathrm{C}$ in the presence of $200 \mu \mathrm{g} / \mathrm{ml}$ cationized ferritin (Sigma Chemical Co., St. Louis, MO, USA) dissolved in DMEM without serum. The cells were then washed in PBS, $\mathrm{pH}$ 7.2 , at $4^{\circ} \mathrm{C}$ and infected with parasites (10:1 parasite-host cell ratio) for periods varying from 15 to $60 \mathrm{~min}$ at $37^{\circ} \mathrm{C}$ in a $5 \% \mathrm{CO}_{2}$ atmosphere. The cells were rinsed twice with PBS, $\mathrm{pH} 7.2$, to remove extracellular parasites and processed for transmission electron microscopy.

UEA I lectin binding sites labeling before interaction - The HUVEC cultures were incubated for $30 \mathrm{~min}$ at $4^{\circ} \mathrm{C}$ in the presence of UEA I lectin, $\mathrm{pH} 7.2$, conjugated with fluorescein isothiocyanate (FITC) or with colloidal gold particles (10 nm) (Sigma Chemical Co., St. Louis, MO, USA). The labeled cells were then infected with parasites (10:1 parasite-host cell ratio) for periods varying from 15 to $60 \mathrm{~min}$ at $37^{\circ} \mathrm{C}$ in $5 \% \mathrm{CO}_{2}$ atmosphere. After interaction time, the cells were washed twice in PBS, pH 7.2, to remove extracellular parasites, fixed in $4 \%$ paraformaldehyde in PBS, $\mathrm{pH} 7.2$, for $30 \mathrm{~min}$ and prepared for confocal microscopy or processed for transmission electron microscopy. Noninfected cells were used as control.

UEA I lectin binding sites labeling after interaction The HUVEC cultures were incubated with parasites (10:1 parasite-host cell ratio) for periods varying from 15 to 60 min at $37^{\circ} \mathrm{C}$ in $5 \% \mathrm{CO}_{2}$ atmosphere. The cells were then washed twice in PBS, pH 7.2 to remove extracellular parasites, fixed in $4 \%$ paraformaldehyde in PBS, $\mathrm{pH} 7.2$, for 30 min and permeabilized with acetone at $-20^{\circ} \mathrm{C}$ for $5 \mathrm{~min}$. The cells were incubated for $1 \mathrm{~h}$ in the presence of UEA I lectin, pH 7.2, conjugated with FITC (Sigma Chemical Co., St. Louis, MO, USA) and prepared for confocal micros- copy. Noninfected cells were used as control.

Class I HLA labeling - The HUVEC cultures were incubated with parasites (10:1 parasite-host cell ratio) for periods from $15 \mathrm{~min}$ to $24 \mathrm{~h}$ at $37^{\circ} \mathrm{C}$ in $5 \% \mathrm{CO}_{2}$ atmosphere. The cells were then washed twice in PBS, pH 7.2, to remove extracellular parasites, fixed in $4 \%$ paraformaldehyde in PBS, $\mathrm{pH}$ 7.2, for $30 \mathrm{~min}$ and permeabilized with acetone at $-20^{\circ} \mathrm{C}$ for $5 \mathrm{~min}$. The indirect immunofluorescence technique was employed using a mouse anti-human Class I HLA (DAKO Corporation Carpinteria, CA, USA) as a primary antibody at dilution 1:20 in 1\% buffer saline albumin. The antigen-antibody complex was visualized using a tetramethylrhodamine isothiocyanate (TRITC) conjugated secondary antibody (Sigma Chemical Co., St. Louis, MO, USA). The coverslips were mounted onto slides with fluorescence mounting medium (n-propyl gallate) and observed in a Axiovert 410 Zeiss confocal laser scanning microscope, using a 488 (LP 415 filter) or 543 (LP 570 filter) argon laser (Carl Zeiss, Oberkochen, Germany).

Transmission electron microscopy - After interaction with $T$. gondii, the cultures were fixed in $2 \%$ glutaraldehyde and $4 \%$ paraformaldehyde solution in $0.1 \mathrm{M}$ cacodylate buffer, $\mathrm{pH} 7.2$, with $5 \mathrm{mM} \mathrm{CaCl}_{2}$ for $2 \mathrm{~h}$ at room temperature. Thereafter, the cells were washed overnight with $0.1 \mathrm{M}$ cacodylate buffer, $\mathrm{pH} 7.2$, and then scraped off with a rubber policeman, collected by centrifugation and postfixed in $1 \% \mathrm{OsO}_{4}$ solution containing $0.8 \%$ potassium ferricyanide in $0.1 \mathrm{M}$ cacodylate buffer, $\mathrm{pH} 7.2$, supplemented with $5 \mathrm{mM} \mathrm{CaCl}_{2}$ for $40 \mathrm{~min}$ at room temperature, dehydrated in acetone and embedded in Epon. Ultrathin sections were stained with uranyl acetate and lead citrate, then examined with an EM 906 Zeiss transmission electron microscope of Uerj.

\section{RESULTS}

Anionic sites labeling - HUVEC cultures were incubated for $30 \mathrm{~min}$ at $4{ }^{\circ} \mathrm{C}$ in the presence of cationized ferritin and then infected with tachyzoites of $T$. gondii for 15 to $60 \mathrm{~min}$ at $37^{\circ} \mathrm{C}$. No cationized ferritin binding sites were seen in the membrane lining the PV. However, small vesicles labeled with ferritin particles were located close to the parasite-containing vacuole (Fig. 1).

UEA I lectin binding sites labeling - The UEA I lectin was used as marker for HUVEC since human endothelial cells contain exposed fucose residues (Holthöfer et al. 1982). When the host cells were previously labeled with UEA I lectin conjugated with FITC and then allowed to interact with the parasites for periods varying from 15 to $60 \mathrm{~min}$ or the host cells were labeled after infection, no labeling was seen in the membrane lining endocytic vacuoles containing the parasite. However, many small vesicles located close to the PV, showed the presence of lectin. Noninfected host cells used as control, showed a uniform labeling on the whole cell surface (data not shown). These results observed by confocal microscopy were confirmed by transmission electron microscopy. When HUVEC cultures were incubated for $30 \mathrm{~min}$ at $4{ }^{\circ} \mathrm{C}$ with gold-labeled UEA I lectin and infected with tachyzoites forms of $T$. gondii for 15 to $60 \mathrm{~min}$ at $37^{\circ} \mathrm{C}$, the labeling was absent in the PVM, but some vesicles containing UEA I-colloidal 


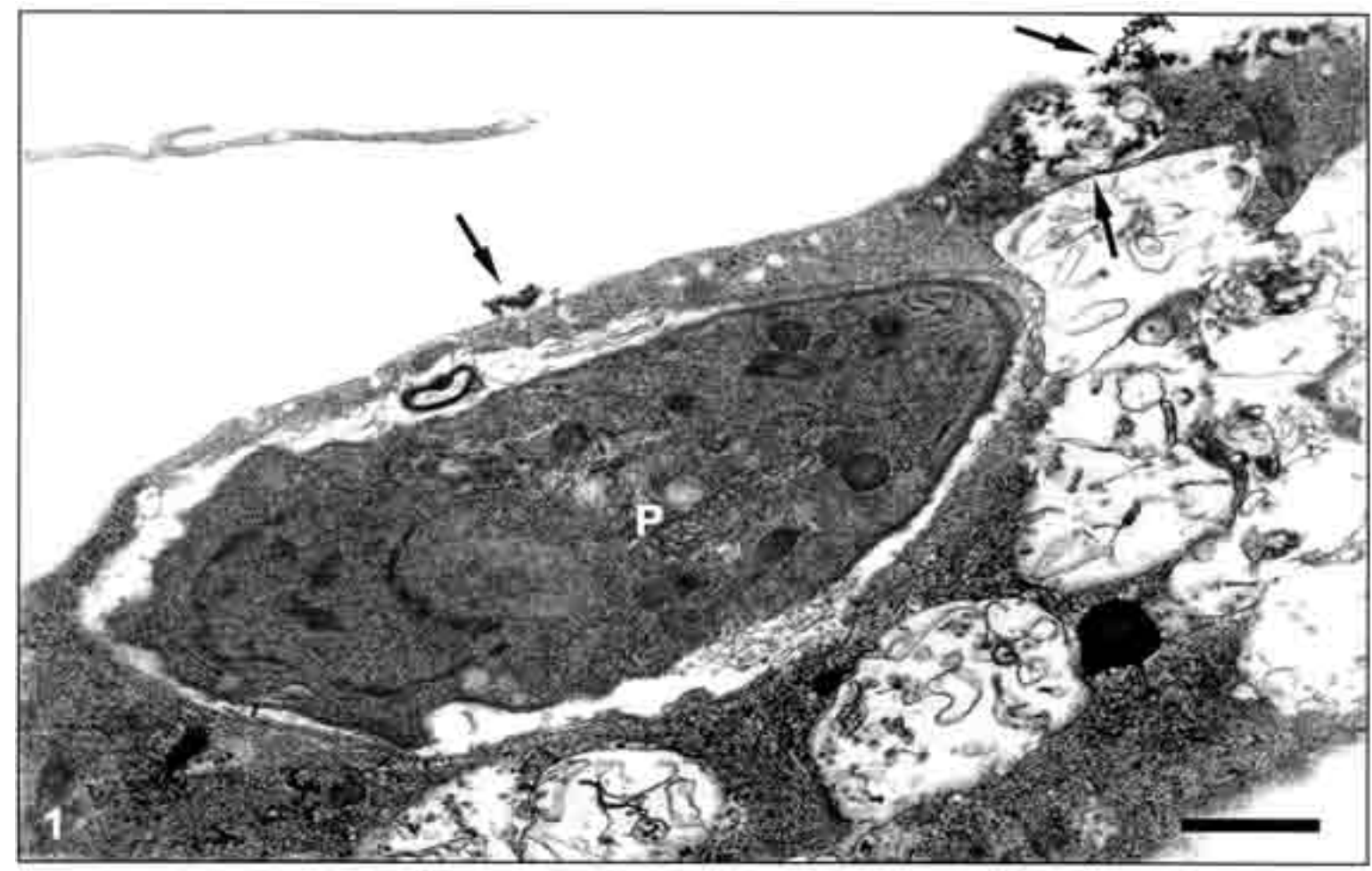

Fig.1: transmission electron micrograph of human umbilical endothelial cells labeled with cationized ferritin at $4^{\circ} \mathrm{C}$ and then incubated with Toxoplasma gondii $(\mathrm{P})$ at $37^{\circ} \mathrm{C}$ for $15-30 \mathrm{~min}$. The ferritin particles (arrows) are seen on the plasma membrane and within vesicles, but there are no particles in PV. Bar $=0.5 \mu \mathrm{m}$

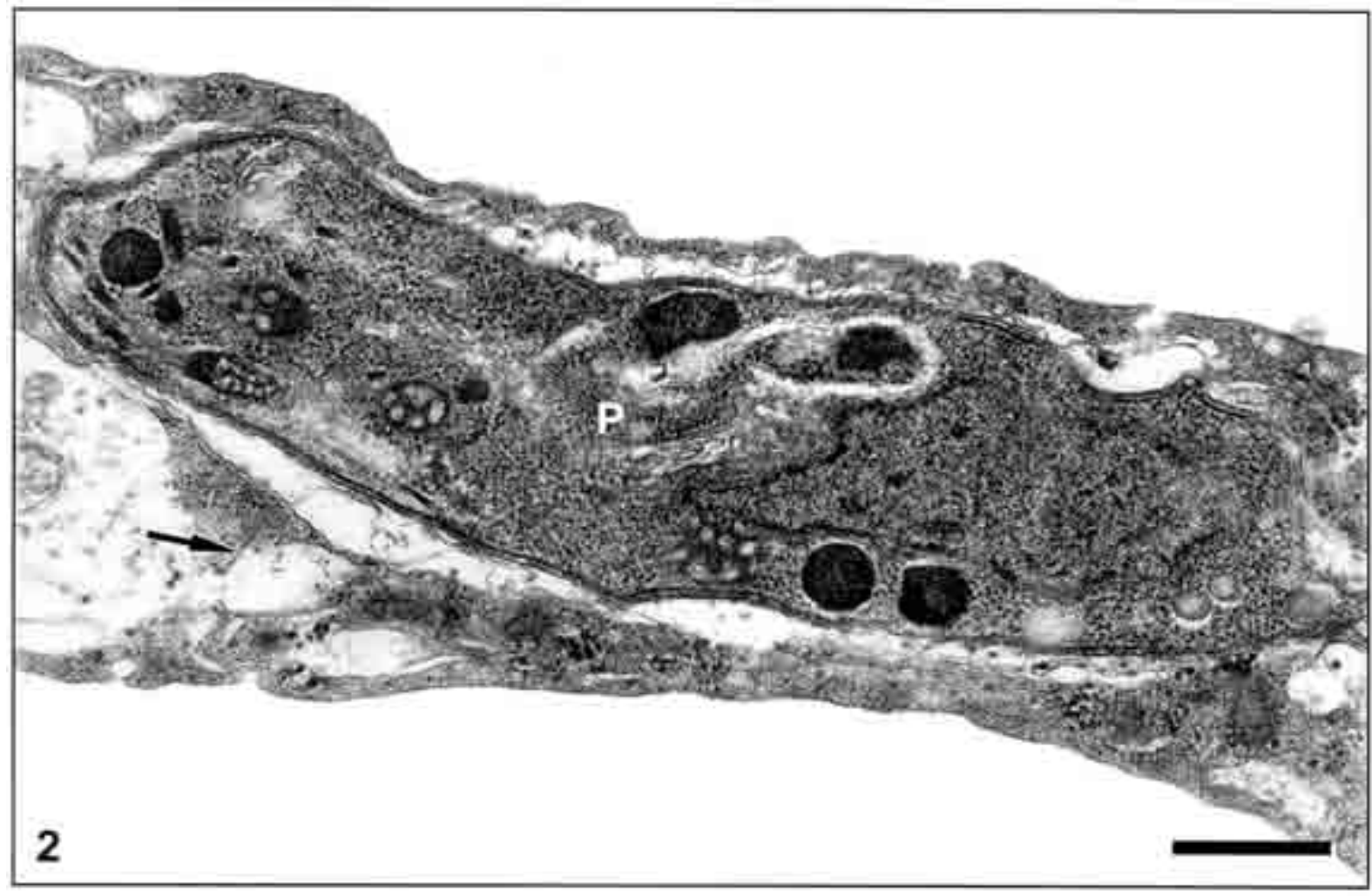

Fig.2: transmission electron micrograph of human umbilical vein endothelial cells incubated with gold-labeled UEA I at $4^{\circ} \mathrm{C}$ and then infected with Toxoplasma gondii $(\mathrm{P})$ at $37^{\circ} \mathrm{C}$. After 15-30 min of interaction, gold particles (arrow) are observed in small vesicles localized near the PV. Bar $=0.5 \mu \mathrm{m}$ 

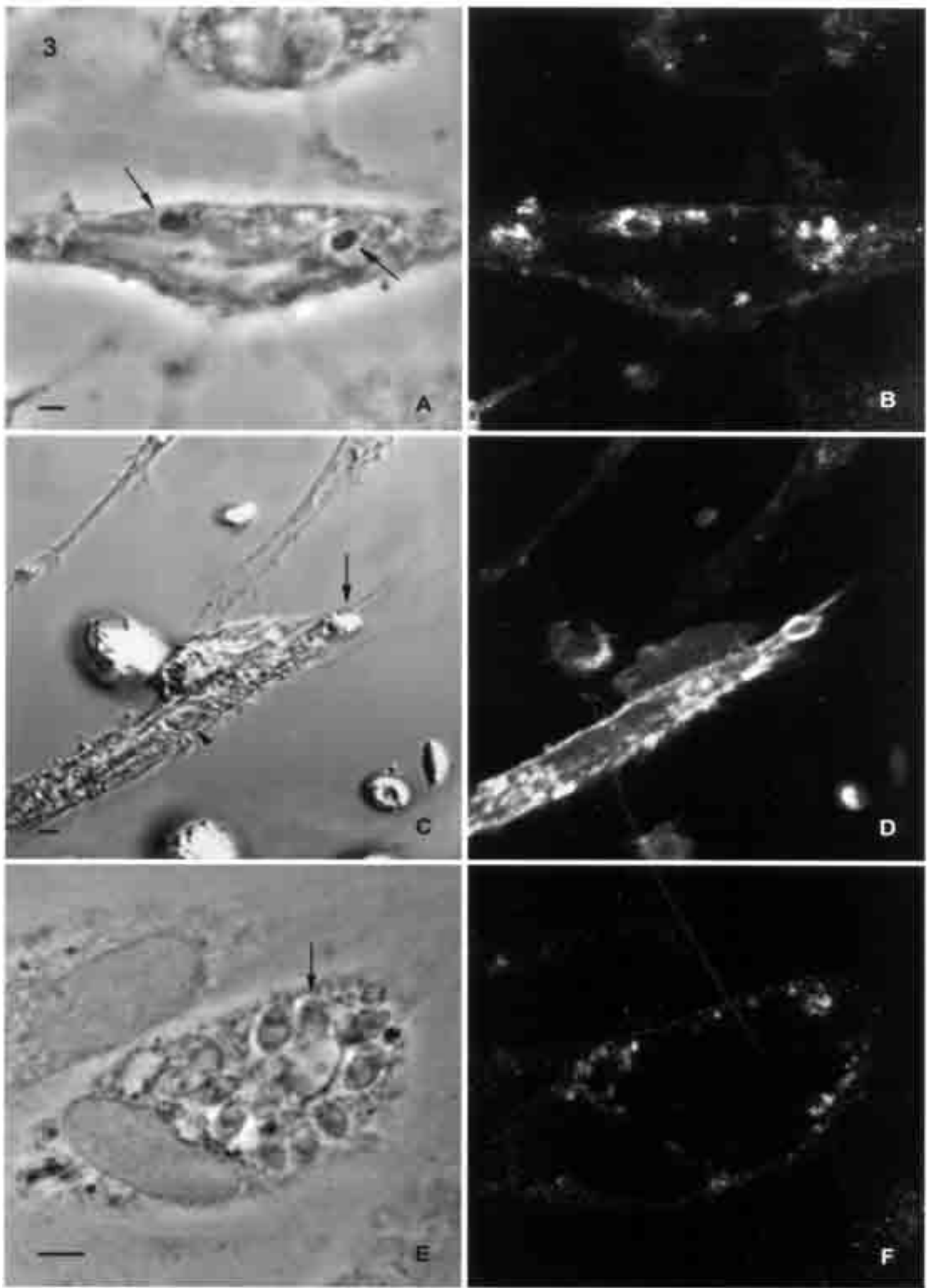

Fig.3: confocal laser scanning microscopy of human umbilical vein endothelial cells infected with Toxoplasma gondii, incubated with mouse anti-Class I human leukocyte antigen and then with goat-anti-mouse conjugated to tetramethylrhodamine isothiocyanate. After 15 and $30 \mathrm{~min}$ of interaction (A-B) and $1 \mathrm{~h}(\mathrm{C}-\mathrm{D})$, the labeling is observed surrounding some parasitophorous vacuole (PV) (arrows) and not others (arrowhead). Extracellular parasites are seen with no labeling (white arrows). After $24 \mathrm{~h}$ of interaction (E-F), small-labeled vesicles are seen near the PV (arrow). Bar $=5 \mu \mathrm{m}$ 
gold particles were located close to the PV (Fig. 2).

Class I HLA labeling - Class I HLA molecules are present in most of the eukaryotic cells and play an important role in the immune response regulation. HUVEC cultures were incubated with anti-HLA I after infection with $T$. gondii for periods varying from $15 \mathrm{~min}$ to $24 \mathrm{~h}$. Our results observed by confocal laser scanning microscopy showed the labeling only on a minority of PV during the beginning of interaction with $T$. gondii $(15 \mathrm{~min}-1 \mathrm{~h})$. However, after $24 \mathrm{~h}$ parasite-host cell interaction, the labeling was observed only in small vesicles near PV (Fig. 3A-F).

\section{DISCUSSION}

Previous studies (Woodman et al. 1991, Dimier \& Bout 1993, 1996, Benedetto et al. 1997) have shown that T. gondii invades and proliferates in in vitro HUVEC cultures. The biogenesis of PV during T. gondii-endothelial cell interaction has not been detailed. We showed here that anionic sites revealed with ferritin cationized particles were not internalized together with $T$. gondii tachyzoites during its interaction with endothelial cells. These results were different of those that we previously showed when cationized ferritin-labeled macrophages were incubated in the presence of $T$. gondii and these ferritin particles were internalized together with the parasite (Carvalho \& De Souza 1990). These observations support the view that host cells, professional and non-professional phagocytic cells, present different behaviour with regard to internalization of the anionic sites during the PV formation and these surface components do not interfere with survival of this parasite.

The employ of the UEA I lectin as marker for HUVEC and its fate during the interiorization of $T$. gondii showed no internalization of UEA I lectin binding sites during the PV formation. These data provide further evidence that distinct mechanisms control the host cell plasma membrane components that are interiorized together with the parasite. This idea is supported by previous demonstration that some enzymes (Carvalho \& De Souza 1989) or sugar residues (Carvalho \& De Souza 1997, PachecoSoares \& De Souza 2000) associated with the plasma membrane of macrophages are not found in the membrane lining the PV containing $T$. gondii.

Recently, we demonstrated that the immunofluorescence of HUVEC with anti-HLA-ABC showed a granular pattern concentrated around the nucleus or diffuses along the cytoplasm (Pontes et al. 2001). In order to analyze if the class I HLA transmembrane glycoprotein of the human endothelial cell is internalized and become part of the PVM, we used monoclonal antibody against HLA I. Our results showed that the labeling was present only on a minority of PV in the beginning of the interaction with $T$. gondii. These few vacuoles labeled with anti-HLA I were probably formed during a typical phagocytic process. Our present observations are in agreement with previous studies which showed that during uptake of both opsonized and dead $T$. gondii, macrophage plasma membrane class I MHC molecules were present on a minority of Toxoplasma-containing phagosomes (Mordue \& Sibley 1997).

We also showed $24 \mathrm{~h}$ after T. gondii-endothelial cell interaction the absence of HLA I molecule expression on the plasma membrane surface as well as in the PVM. However, the labeling was observed only in small vesicles near PV. Previous studies showed that host cell transmembrane proteins, including $\mathrm{Na}^{+}-\mathrm{K}^{+}$-ATPase, $\mathrm{Mg}^{++}$-ATPase, 5'nucleotidase, and CD44 are excluded from the parasitophorous vacuole membrane (Carvalho \& De Souza 1989, Mordue et al. 1999a), and probably this exclusion occurs due to a mechanism that depends on protein anchoring in the plasma membrane (Mordue et al. 1999a). These data suggest that during the interaction $T$. gondiinon professional phagocytic cells as the endothelial cells studied here, the parasite can participate of the mechanism of block in the Class I HLA antigen presentation pathway. This event probably is similar to that occur in $T$. gondii-phagocyte interaction, where intracellular $T$. gondii interferes with the Class I and Class II MHC antigen presentation pathway of murine macrophages and this may be an important strategy for evasion from host's immune response and for intracellular survival of the parasite (Lüder et al. 1998).

In conclusion, our preliminary experiments about $T$. gondii-endothelial cells interaction showed that anionic sites, fucose residues and HLA I molecules were probably excluded from the region where the active penetration process took place and the absence of these surface components in the PVM do not interfere with survival and multiplication of $T$. gondii tachyzoites within the endothelial cells.

\section{ACKNOWLEDGMENTS}

To the staff from the Instituto Municipal da Mulher Fernando Magalhães for providing the umbilical cords, and to the Laboratório de Biologia Celular e Tecidual, Uenf, for the use of Axiovert 410 Zeiss confocal laser scanning microscope.

\section{REFERENCES}

Benedetto N, Folgore A, Ferrara C, Molitierno M, Galdiero F 1997. Effects of alpha-adrenergic agonists on Toxoplasma gondii replication in human umbilical vein endothelial cells. Pathol Biol 45: 9-18.

Carvalho L, De Souza W 1989. Cytochemical localization of plasma membrane enzyme markers during interiorization of tachyzoites of Toxoplasma gondii by macrophages. $J$ Protozool 36: 164-170.

Carvalho L, De Souza W 1990. Internalization of surface anionic sites and phagosome-lysosome fusion during interaction of Toxoplasma gondii with macrophages. Eur J Cell Biol 51: 211-219.

Carvalho L, De Souza W 1997. Carbohydrate-containing molecules found in rhoptries are released during active penetration of tachyzoites of Toxoplasma gondii in host cells. Biocell 21: 27-31.

Carvalho L, Yan CYI, De Souza W 1993. The effect of various digestive enzymes on the interaction of Toxoplasma gondii with macrophage. Parasitol Res 79: 114-118.

Dimier IH, Bout DT 1993. Co-operation of interleukin-1 $\beta$ and tumor necrosis factor- $\alpha$ in the activation of human umbilical vein endothelial cells to inhibit Toxoplasma gondii replication. Immunology 79: 336-338.

Dimier IH, Bout DT 1996. Inhibitory effect of interferon-gamma activated ovine umbilical vein endothelial cells on the intracellular replication of Toxoplasma gondii. Vet Res 27: 527534.

Hakansson S, Charron AJ, Sibley LD 2001. Toxoplasma 
evacuoles: a two-step process of secretion and fusion forms the parasitophorous vacuole. EMBO J 20: 3132-3144.

Holthöfer H, Virtanen I, Kariniemi AL, Hormia M, Linder E, Miettinen A 1982. Ulex europaeus I lectin as a marker for vascular endothelium in human tissues. Lab Invest 47: 6066.

Jaffe EA, Hoyer L, Nachman RL 1974. Synthesis of von Willebrand factor by cultured human endothelial cells. Proc Nalt Acad Sci USA 71: 1906-1909.

Jaffe EA, Nachman RL, Becker CG, Minick RC 1973. Culture of human endothelium cells derived from umbilical veins: identification by morphologic and immunologic criteria. $J$ Clin Invest 52: 2745-2756.

Jones TC, Hirsch JG 1972. The interaction between T. gondii and mammalian cells. II. The absence of lysosomal fusion with phagocytic vacuoles containing living parasites. $J$ Exp Med 136: 1173-1194.

Lingelbach K, Joiner KA 1998. The parasitophorous vacuole membrane surrounding Plasmodium and Toxoplasma: an unusual compartment in infected cells. J Cell Sci 111: 14671475.

Lüder CGK, Lang T, Beuerle B, Groos U 1998. Down-regulation of MHC class II molecules and inability to up-regulate class I molecules in murine macrophages after infection with Toxoplasma gondii. Clin Exp Immunol 112: 308-316.

Luft BJ, Chua A 2000. Central nervous system toxoplasmosis in HIV pathogenesis, diagnosis and therapy. Curr Infect Dis Rep 2: 358-362.

Luft BJ, Remington JS 1992. Toxoplasmic encepphalits in AIDS. Clin Infect Dis 15: 11-12.

Mordue DG, Sibley LD 1997. Intracellular fate of vacuoles containing Toxoplasma gondii is determined at the time of formation and depends on the mechanism of entry. $J$ Immunol 159: 4452-4459.

Mordue DG, Desai N, Dustin M, Sibley LD 1999a. Invasion by Toxoplasma gondii establishes a moving junction that selectively excludes host cell plasma membrane proteins on the basis of their membrane anchoring. J Exp Med 190: 1783-1792.

Mordue DG, Hakansson S, Niesman I, Sibley LD 1999b. Toxoplasma gondii resides in a vacuole that avoids fusion with host cell endocytic and exocytic vesicular trafficking pathways. Exp Parasitol 92: 87-99.
Nichols BA, Chiappino ML, O’Connor GR 1983. Secretion from the rhoptries of Toxoplasma gondii during host-cell invasion. J Ultrastruct Res 83: 85-98.

Pacheco-Soares C, De Souza W 1998. Redistribution of parasite and host cell membrane components during Toxoplasma gondii invasion. Cell Struct Funct 23: 159-168.

Pacheco-Soares C, De Souza W 2000. Localization of saponinsterol complexes and lectin-binding sites during interaction of Toxoplasma gondii with host cells. Parasitol Res 86: 529-536.

Pontes LFS, Carvalho L, Stumbo AC, Porto LC 2001. Detection and localization of non-HLA-ABC antigenic sites relevant to kidney rejection on endothelial cells. J Immunol Met 251: 73-80.

Sibley LD 1989. Active modification of host cell phagosomes by Toxoplasma gondii. In JW Moulder, Intracellular Parasitism, CRC Press Inc., Florida, p. 245-257.

Sibley LD 1994. Interactions between Toxoplasma gondii and its mammalian host cells. Semin Cell Biol 4: 335-344.

Silverman JA, Joiner KA 1997. Toxoplasma/Host-cell interactions. In SHE Kaufmann, Host Response to Intracellular Pathogens, RG Landers Company, Austin, p. 313-338.

Sinai AP, Joiner KA 1997. SAFE HAVEN: The Cell Biology of Nonfusogenic Pathogen Vacuoles. Annu Rev Microbiol 51: 415-462.

Sinai AP, Joiner KA 2001. The Toxoplasma gondii protein ROP 2 mediates host organelle association with the parasitophorous vacuole membrane. J Cell Biol 154: 95108.

Sinai AP, Webster P, Joiner, KA 1997. Association of host cell endoplasmic reticulum and mitochondria with the Toxoplasma gondii parasitophorous vacuole membrane: a high affinity interaction. J Cell Sci 110: 2117-2128.

Suss-Toby E, Zimmerberg J, Ward GE 1996. Toxoplasma invasion: the parasitophorous vacuole is formed from host cell plasma membrane and pinches off via a fusion pore. Proc Natl Acad Sci USA 93: 8413-8418.

Woodman JP, Dimier IH, Bout DT 1991. Human endothelial cells are activated by IFN-gamma to inhibit Toxoplasma gondii replication. Inhibition is due to a different mechanism from that existing in mouse macrophages and human fibroblasts. J Immunol 147: 2019-2023. 